\title{
ESTÉTICAS COTIDIANAS ESCOLARES: DESDE LO QUE SE VE HACIA CÓMO SE SIENTE LA ESCUELA*
}

\author{
Guillermo Marini ${ }^{1}$ \\ Juan David Rodríguez Merchán ${ }^{1}$ \\ Macarena Salas Aguayo ${ }^{1}$
}

\begin{abstract}
RESUMEN: Este artículo plantea la relevancia educativa de las estéticas cotidianas escolares. En primer lugar, a partir de dos imágenes como ejemplo, se presenta la noción de matriz estética escolar, en tanto criterio de organización de la sensibilidad en los entornos escolares. En segundo lugar, desde los estudios visuales, discute la noción de cultura visual escolar, describiendo otras tres imágenes que dan cuenta de la relación entre lo visual y la visualidad. Finalmente, explora la convergencia entre algunos elementos del clima escolar, la estética cotidiana y la cultura visual, problematizando la relación entre lo que se ve y cómo se siente la escuela.
\end{abstract}

Palabras clave: Estética cotidiana. Estética escolar. Cultura visual escolar. Clima escolar.

\section{EVERYDAY SCHOOL AESTHETICS: \\ FROM WHAT IS SEEN TOWARDS HOW ONE FEELS AT SCHOOL}

ABSTRACT: This paper proposes the educational relevance of everyday school aesthetics. Firstly, through two visual examples, the notion of school aesthetic matrix is introduced as a criterion that organizes the sensibility of school environments. Second, based on visual studies, the visual culture of schools is discussed by means of three images that portray the relationship between visual and visuality. Finally, the connection between elements of school climate, everyday aesthetics and visual culture is explored to examine the relationship between what is seen, and how one feels at school.

Keywords: Everyday aesthetics. School aesthetics. Visual culture of schools. School climate.

\footnotetext{
*Este artículo discute algunos hallazgos de la investigación "Estética visual y clima escolar: hacia una comprensión educativa del entorno escolar" financiada por CONICYT Fondecyt de Iniciación No11150459. ${ }^{1}$ Pontificia Universidad Católica de Chile, Facultad de Educación - Santiago, Chile.

E-mails: gmarini@uc.cl, jdrodriguez1@uc.cl, msalas1@uc.cl

DOI: 10.1590/ES0101-73302018171876
} 


\section{ESTHETIQUES QUOTIDIENNES SCOLAIRES: DE CE QUE L'ON VOIT A CE QUE COMMENT L'ON SE RESSENT A L'ECOLE}

RÉSUMÉ: Cet article aborde le rôle de l'esthétique du quotidien dans le milieu scolaire. À la lumière des contributions de l'esthétique $\mathrm{du}$ quotidien, nous présentons premièrement la notion de matrice esthétique scolaire en tant critère d'organisation de la sensibilité dans les milieux scolaires et proposons deux images comme exemple. Ensuite, en revisitant les études visuelles, la notion de culture visuelle à l'école sera abordée en décrivant trois images qui rendent compte de la relation entre le visuel et la visualité. Finalement, cet article explore la confluence entre certains éléments du climat scolaire, l'esthétique du quotidien et la culture visuelle en problématisant la relation entre ce que l'on voit et comment l'on se ressent à l'école.

Mots-clés: Esthétique quotidienne. Esthétique de l'école. Culture visuelle scolaire. Climat scolaire.

\section{Introducción}

$\mathrm{L}$

as presiones que sufren los sistemas educativos por demostrar resultados que cumplan con las expectativas que recaen sobre ellos, hacen que frecuentemente se distraiga la atención sobre cuáles son los fundamentos y sentidos de la educación. Ahora bien, los límites epistemológicos y técnicos del accountability y evaluación escolar no tienen por qué convertirse en los límites de aquello que se considere valioso en la educación (BIESTA, 2014).

Por ejemplo, si bien es evidente el peso que tienen las pruebas estandarizadas estatales, las mediciones nacionales de gestión y administración educativa, y los estudios internacionales comparados como TIMMS y PISA, lo cierto es que estas aproximaciones al mundo de la educación escolar tienden a mirar la escuela a través de productos alfanuméricos; parafraseando a Viktor Lowenfeld, 26 letras y 10 números parecen representar los únicos recursos disponibles desde los cuales se enseña a los niños y niñas a interpretar y recrear su mundo (LOWENFELD, 1970, p. 47). Es relevante entonces preguntarse qué otros modos de aproximarse a la educación pueden existir más allá de estos 36 símbolos.

En este sentido, llama la atención la escasa investigación dedicada a explorar el desarrollo de la percepción sensible en la escuela. Aunque vivimos en una época hiperestimulada de sensaciones de todo tipo, no es claro cómo aprovechar tales estímulos en favor de una experiencia educativa más rica. De hecho, las imágenes se multiplican con mucha mayor velocidad que la capacidad para analizarlas y criticarlas (MIRZO- 
EFF, 1999). Elliot Eisner solía comentar, al respecto, que "crecer en una cultura es un camino que nos enseña a mirar, como así también a no mirar" (EISNER, 2006, p. 11). Vinculando estos argumentos, se podría afirmar que la escuela parece haber enfocado su mirada sobre números y letras, desatendiendo o ignorando la percepción de su propio entorno - desplegada en imágenes visuales, sabores, olores, sonidos y texturas - así como la de aquellos que la habitan diariamente. Ante esto, detenerse en las estéticas cotidianas escolares podría contribuir a promover una alfabetización sensible ${ }^{1}$ que permitiera vincular a los sujetos más lúcidamente consigo mismos y con su entorno.

\section{Estéticas cotidianas escolares}

La estética cotidiana atiende a los estímulos básicos que constituyen la experiencia diaria. A diferencia de la filosofía del arte y su preocupación histórica por la belleza, la fealdad, el juicio estético, lo sublime, etc., la estética cotidiana se ocupa de la percepción de los colores, olores, sonidos y texturas que están presentes en la mesa del desayuno, nuestras ropas, el camino hacia el trabajo, nuestros espacios de estudio y ocio, entre otros eventos habituales que implican una dimensión sensible (MARINI, 2016; LEDDY, 2012; SAITO, 2007; DEWEY, 1934). Por lo mismo, es siempre plural, es decir, refiere a "estéticas cotidianas" ya que, si bien un objeto de percepción puede ser común a distintos sujetos, los modos de percibir dicho objeto y las relaciones entre quienes perciben de esos modos, son de suyo diversos como se ejemplificará más adelante.

Si bien la estética cotidiana parece muchas veces invisible o "negativa" a primera vista (DOWLING, 2010), su contribución a la educación puede ser significativa ya que facilitaría el acercamiento a la sensibilidad como modo de conocer (EISNER, 2009; SHUSTERMAN, 2008), promoviendo la vinculación entre percepción y las estructuras de nuestra conciencia (DAMASIO, 2000; 2010). Considérese el ejemplo extremo de los ciego-sordo-mudos quienes, como Helen Keller, se aferran a un solo sentido para descubrir el circuito entre la sensibilidad del mundo exterior - los símbolos e imágenes producto de esa sensibilidad - y la conciencia de sí mismos. En el caso particular de Keller, fue el frío fluir del agua de un pozo de campo lo que detonó la relación entre el agua - el signo de agua que su maestra había trazado tantas veces en su mano - y ella quien sentía que sentía el agua. En un milagro cotidiano, Helen sintió al agua, entendió el signo y se supo mujer (SULLIVAN, 1887). Por lo mismo, resulta relevante y pertinente considerar en cuáles ámbitos de la educación sería posible aproximarnos hacia la estética cotidiana.

En este sentido, posiblemente el entorno escolar construido sea la materia primera, más común y accesible a todos los estudiantes, profesores y directivos desde la cual indagar la estética cotidiana. Aunque la preocupación histórica sobre la infraestructura escolar ha estado ceñida a que el edificio cumpla con requisitos mínimos de habitabilidad en materia de calidad del aire, acústica, ventilación y 
aislación térmica (BAKER, 2012), la literatura demuestra un creciente interés en la aproximación estética a la cotidianeidad del entorno escolar (ERRÁZURIZ, 2015a; 2015b; PINEAU, 2014).

En términos concretos, sería posible comenzar una aproximación hacia las estéticas cotidianas escolares a través de la elaboración, descripción y análisis de "matrices estéticas", en tanto criterios para la organización de la sensibilidad (MANDOKI, 2007, p. 177-182). Si se consideran ciertos aspectos de la escuela tales como tamaño, materialidades, fachada, símbolos institucionales, forma de las salas de clase, dispositivos de juego, plantas y áreas verdes, entre otras; y algunas decisiones pedagógicas como el modo en que el tiempo escolar está organizado, cómo se usa el mobiliario pedagógico, la distribución de los espacios de aprendizaje, la ubicación y altura de los diarios murales, etc., se podrían identificar patrones o rutinas sensibles que diferenciarían a una escuela de otra. En pocas palabras, las matrices estéticas escolares permitirían profundizar la comprensión de los diversos proyectos educativos desde los aspectos sensibles que se configuran en relación al espacio escolar.

Por ejemplo, cuando se dice coloquialmente que una escuela es un "depósito”, y se evocan imágenes como las presentadas más abajo (Figuras 1 y 2),

\section{Figura 1}

Pasillo principal, desde el patio hacia la puerta de entrada. Escuela Básica, 96 estudiantes de 1 a 8 grado, en Santiago de Chile. Financiamiento compartido.

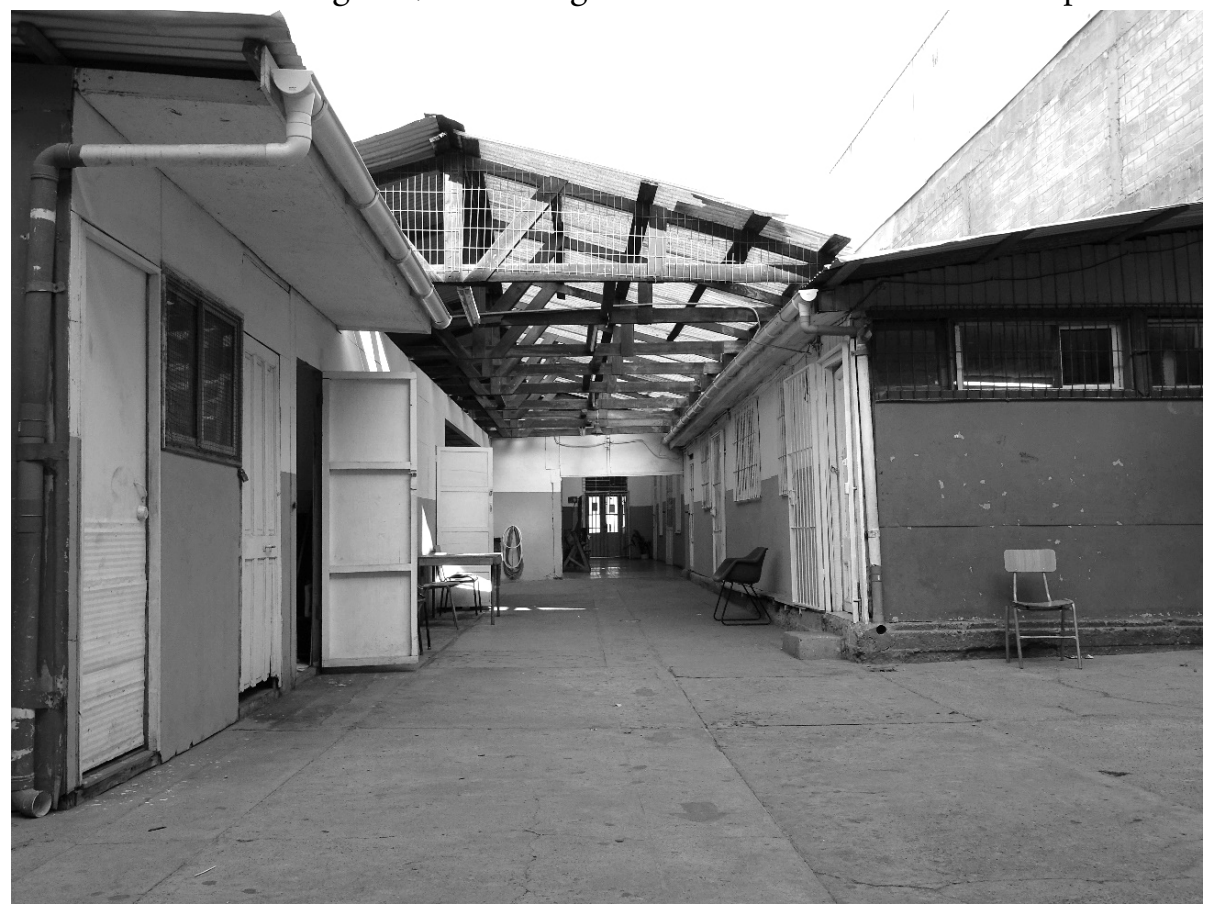

Fuente: Juan David Rodriguez Merchán, fotografias tomadas durante la investigación. 
se está frente al potencial descriptivo y crítico de las matrices estéticas escolares. Siguiendo a Mandoki (2007), lo que estas imágenes proponen no es tanto un problema de definición - bien puede hablarse de una escuela "fábrica" o "reformatorio" en lugar de "depósito" -, sino el desafío por asumir lo que ellas sintetizan de la peculiar sensibilidad de esta escuela. Difícilmente se trata de una escuela "club", "hospital" o "casa de familia". Llama la atención la carencia de plantas o áreas verdes y la falta de signos que caracterizan al sistema escolar tales como diarios murales, intervenciones artísticas o señaléticas de seguridad. La ausencia de estas huellas de pertenencia, junto a un aparente descuido en las superficies y terminaciones, sugiere que este es un espacio todavía con potencial de convertirse en un "lugar de vida comunitaria”. Se volverá sobre esta noción más adelante ${ }^{2}$.

Siguiendo con la caracterización de las estéticas cotidianas escolares se puede afirmar que, al menos en Occidente, una de sus cualidades más sobresalientes es un cierto ocularcentrismo del entorno escolar que "alberga al intelecto y al ojo pero ha dejado sin hogar al cuerpo” (PALLASMAA, 2006, p. 19). En el sistema educativo, esto redunda en la presencia de una proxémica que suele ser incapaz de acoger la contextura física de estudiantes y profesores con distintas edades, alturas, pesos y tamańos. En este sentido, es llamativo que aun cuando la organización de las

\section{Figura 2}

Pasillo principal, desde la puerta de entrada hacia el patio. Escuela Básica, 96 estudiantes de 1 a 8 grado, en Santiago de Chile. Financiamiento compartido.

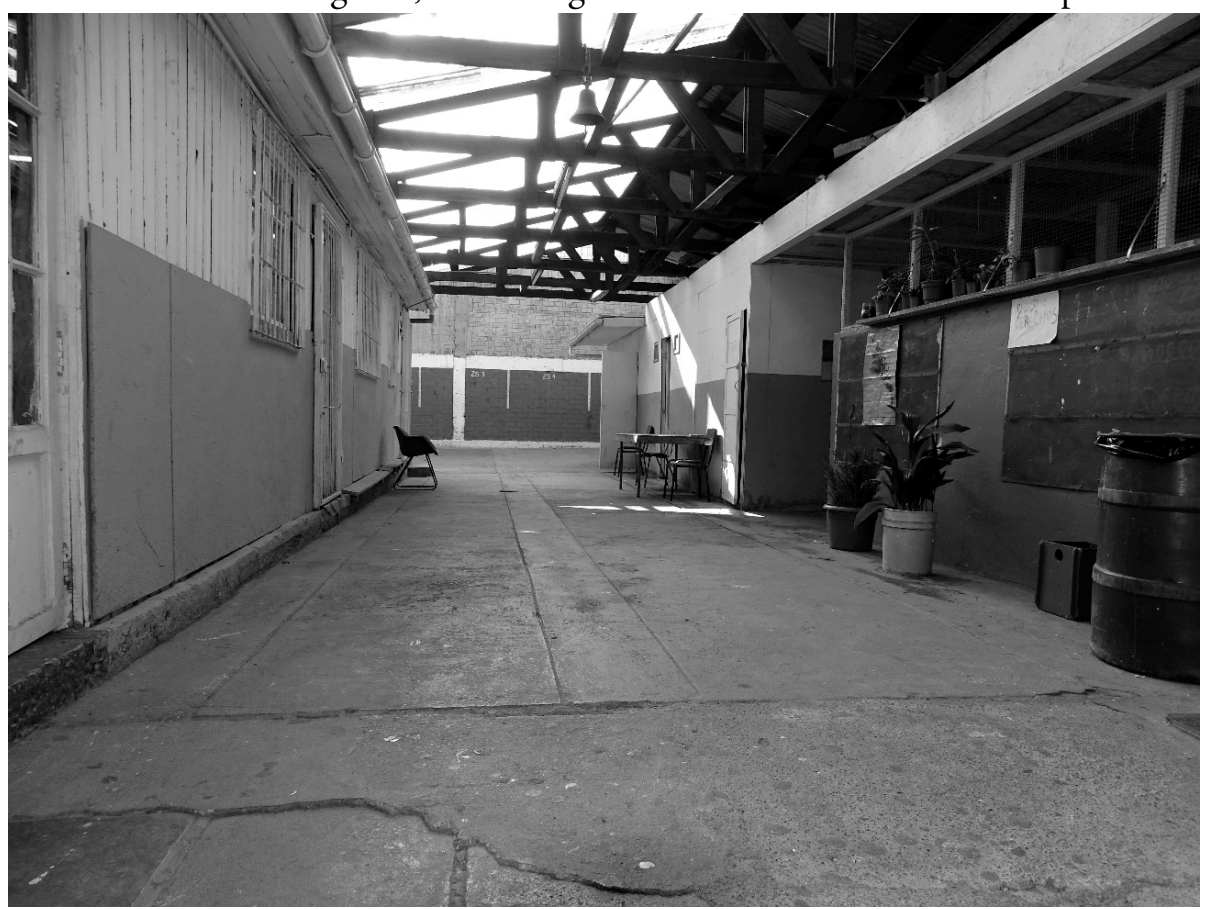

Fuente: Juan David Rodriguez Merchán, fotografias tomadas durante la investigación. 
cohortes o generaciones escolares sigue basándose en la edad de los niños y nińas, las mesas y sillas del establecimiento suelan tener una altura estandarizada.

Frente a esto, existen esfuerzos notables por rescatar al espacio como un verdadero "tercer maestro" (LIPPMAN, 2010, p. 148) que adquiere significado a partir de su apropiación subjetiva (LEHTINEN, 2013). Ahora bien, si atendemos a pedagogías como Waldorf, Reggio Emilia y Montessori - aún consideradas como "no convencionales", especialmente durante la formación Secundaria o Media - es notable su preocupación por la experiencia corpórea de quienes viven la escuela, a la hora de diseñar, construir y utilizar sus espacios. Aquí está manifiesta la decisión por empoderar a los miembros de la escuela haciéndolos habitantes con derecho a intervenir su propio ambiente y no sólo usuarios transitorios del entorno escolar.

Otra cualidad decisiva en las matrices estéticas occidentales, es la gestión del tiempo de modo "monocrónico" (HARGREAVES, 2012, p. 122), dividido por timbres, en bloques cerrados de 45, 50 o 55 minutos, donde el ritmo escolar tiende a ser homogéneo, repetitivo y, por supuesto, escaso para cumplir con todos los requerimientos que se hacen a la escuela. En este sentido, es muy lúcida la lectura que hace Mandoki (2007, p. 244-245) al resaltar que la presencia de los estudiantes suele verificarse únicamente a través de su asistencia y no se repara en la calidad de cómo están presentes en la sala durante el horario correspondiente. Aquí, la concepción del tiempo no puede escapar a una condición que limita desde fuera, de manera objetiva, sin capacidad de atender a los ritmos interiores de los sujetos.

Por el contrario, las estéticas cotidianas podrían relevar aproximaciones desde la experiencia del tiempo vivido. Al considerar este tipo de tiempo, se llamaría la atención sobre tiempos "propios" de re-creación que se sitúan en un registro distinto al de la alternativa aburrimiento / activismo (GADAMER, 1991). Pedagógicamente, esta modalidad de tiempo promovería el enlentecimiento de la experiencia escolar (MARINI, 2015), generando la oportunidad de planificaciones abiertas, flexibles, sensibles al contexto específico de la escuela y a los sucesos del momento (HUSTI, 1992).

En consecuencia, las estéticas cotidianas escolares no sólo pueden contribuir a una exploración más aguda y lúcida de la sensibilidad subjetiva, sino también permitirían ahondar en el entorno escolar en el cual estudiantes, profesores y directivos despliegan y entrecruzan sus propias sensibilidades (HAAPALA, 2005). En otras palabras, "la voz" de quienes viven en dicho entorno podría manifestarse a través de colores, sonidos, olores, texturas y sabores en los soportes materiales y decisiones pedagógicas que definen a una escuela como tal (THOMPSON, 2008, p. 1).

\section{Cultura visual escolar}

Desde las estéticas cotidianas, un desarrollo fundamental para el presente argumento son los estudios visuales. Éstos se caracterizan por "considerar seriamente a las 
imágenes", "reflexionando acerca de las condiciones sociales de las mismas" y "teniendo en cuenta los supuestos epistemológicos desde los cuales se mira" (ROSE, 2012, p. 1). En este marco surge la noción de "cultura visual" como la organización simbólica de aquello que se ve "desde" y "a través" de las imágenes de un entorno determinado.

En este sentido, se ha propuesto que la "cultura visual escolar" está compuesta por los "significados físicos del entorno escolar construido" (PROSSER, 2007, p. 14) y por la "visualidad" o "prácticas del mirar más allá de los hechos que miramos" (STURKEN; CARTWRIGHT, 2001, p. 6) 3. Si se consideran, por ejemplo, las vitrinas de trofeos, diarios murales, posters informativos, los mismos pizarrones, las pantallas digitales o proyecciones multimedia que suelen poblar los establecimientos educativos, todos estos dispositivos aluden tanto a imágenes "que se ven" en la escuela cuanto a intenciones más o menos deliberadas acerca de "cómo debe verse" en dicha escuela.

A partir de estas distinciones Margolis (1999), acuñó la ya famosa noción de "currículum visible pero oculto" aludiendo a un conjunto de contenidos que pretenden ser explícitamente enseñados pero cuyas intencionalidades políticas, sociales y/o ideológicas son frecuentemente subsumidas en "formas de decoración o instrumentos didácticos" (BRYSON, 1988, p. 94). Parecería obvio que las escuelas tengan un sitio como el que muestran las Figuras 3, 4 y 5 donde exhibir las victorias que sus

\section{Figura 3}

Vitrina de trofeos. Escuela Básica y Media, 1388 estudiantes de 1 a 12 grado, en Santiago de Chile. Financiamiento compartido.

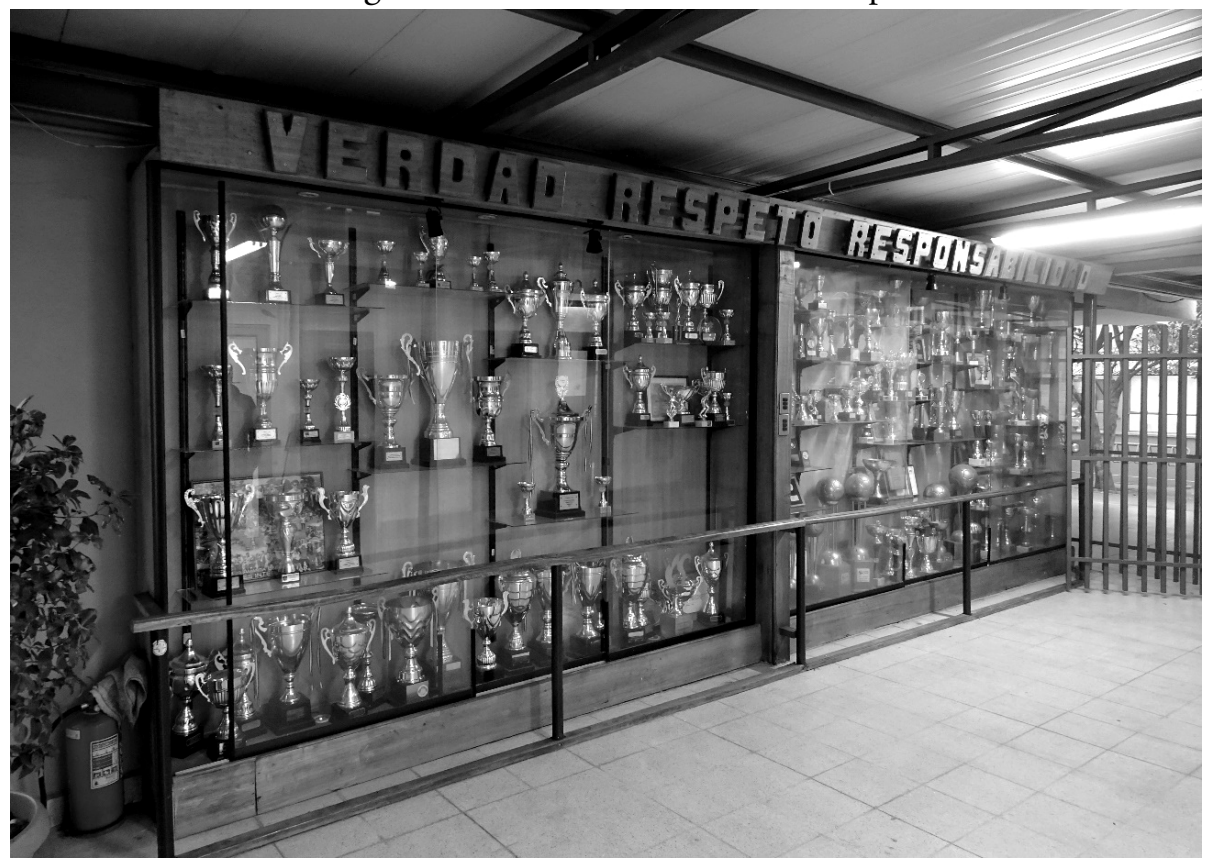

Fuente: Juan David Rodríguez Merchán, fotografias tomadas durante la investigación. 
estudiantes han logrado en certámenes deportivos o artísticos. Éstas podrían servir para reconocer el esfuerzo de quienes las obtuvieron, motivando a otros a emularlos, creando espacios donde se aprecian más que rendimientos académicos o valorando la diversidad de habilidades de la comunidad escolar.

Pero ¡cuáles son los trofeos que se muestran en un estante individual o compartido, a qué altura respecto de la mirada de los niños y adultos, con qué tipo de etiqueta explicativa, cuáles cambian de lugar con el tiempo, son archivados o permanecen fosilizados en su ubicación original, cuáles se ven sucios o rotos pero se mantienen en exhibición, qué reconocimientos se ubican en primer plano, y cuáles son solapados por otros como se nota en las Figuras 4 y 5 ? Si bien todas estas preguntas interrogan a un conjunto de objetos visuales, sus respuestas suponen la visualidad más allá de la materialidad que salta a la vista.

Al día de hoy es importante señalar que existen por lo menos dos perspectivas que expanden y profundizan la noción de "curriculum visible pero oculto". Por una parte, están quienes proponen la existencia de "regímenes de visualidades", orientados por las ideologías dominantes, que se valdrían de las imágenes de la cultura visual escolar para imponer sus modos de mirar la realidad humana. Entre otros exponentes de esta línea, se puede ubicar la crítica de Rancière (2009)

\section{Figura 4}

Vitrina de trofeos. Detalle superior.

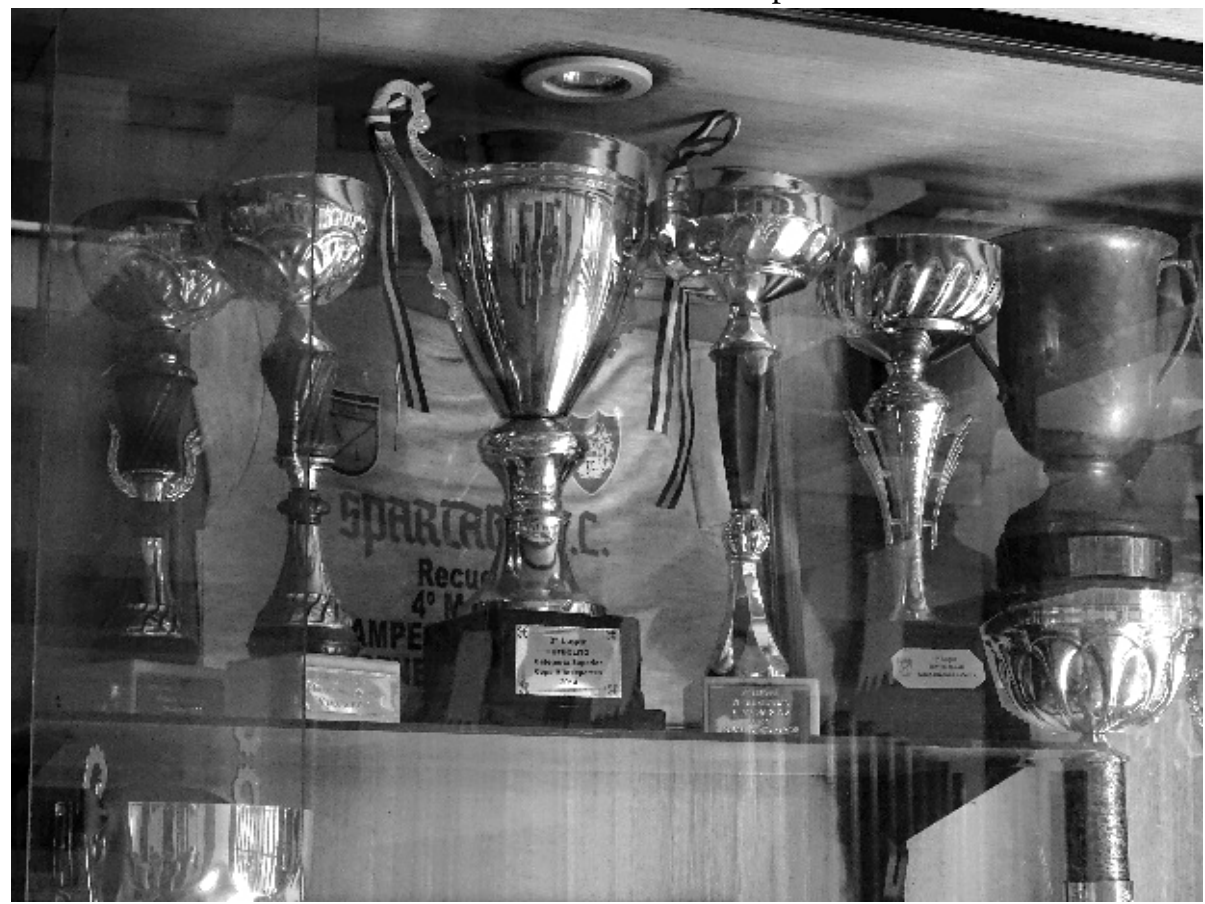

Fuente: Juan David Rodriguez Merchán, fotografias tomadas durante la investigación. 
al régimen de la "división de la sensibilidad", que separa a los que saben saber de los que no, intencionando algunas formas de actividad y de participación, y acallando otras. Desde esta postura, al mirar la figura 3 llama la atención la selección de tres valores (VERDAD, RESPETO, RESPONSABILIDAD), su orden, el hecho que la mayoría de los trofeos estén guardados bajo el aura de la RESPONSABILIDAD, la baranda de contención que permite aproximarse a los trofeos y cuidarlos, a la vez que prohíbe tocarlos, trasladando así su propiedad desde los estudiantes hacia la institución que los exhibe.

Por otra parte, están quienes, sin negar la influencia que los regímenes visuales puedan ejercer sobre la escuela, emplazan su argumento desde una situación de olvido, descuido o falta de atención ante la cultura visual escolar, causada por el inadvertido acostumbramiento de ver siempre una misma cosa ${ }^{4}$. Desde este punto de vista cabe preguntarse si es legítimo hablar de regímenes estéticos en culturas escolares con poca tradición o interés por abordar a la misma escuela como un hecho estético visual (ERRÁZURIZ; MARINI, 2016). Esta desatención es, por lo menos, "curiosa" en una época de exuberancia visual como la nuestra. $\mathrm{Al}$ volver a la Figura 3, la propensión a "mirar sin ver" se constataría en el extinguidor de fuego que descansa en el margen inferior izquierdo, bajo un trapo para

\section{Figura 5}

Vitrina de trofeos. Detalle inferior.

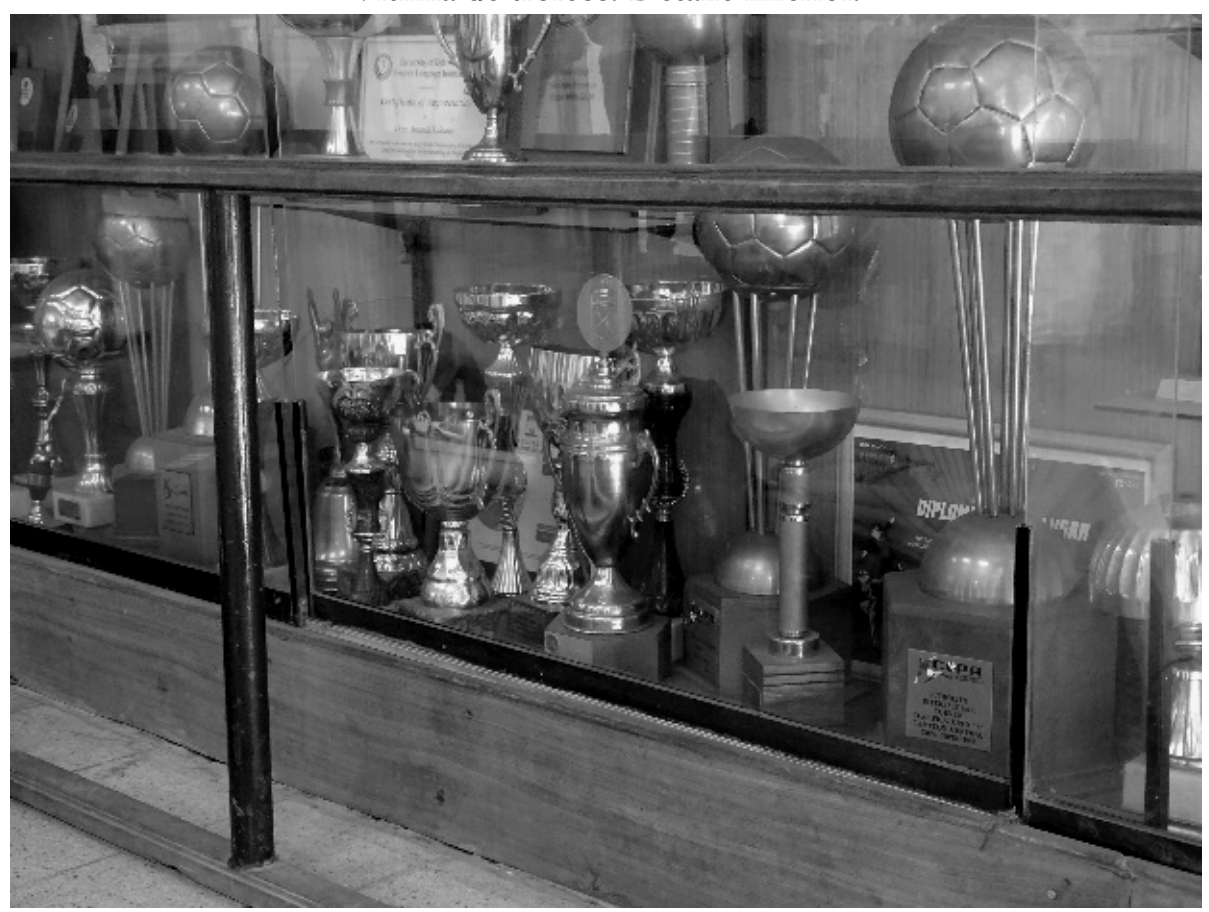

Fuente: Juan David Rodriguez Merchán, fotografias tomadas durante la investigación. 
limpiar el piso, enmarcado por una planta de maceta, junto al impresionante escaparate de premios escolares.

A partir de lo dicho, desafiar la "comprensión inmediata" del "arsenal simbólico escolar" (SMITH, 2008, p. 108) exige el esfuerzo por superar una lectura unívoca de las categorías de análisis estético visual, y abrirse a una consideración análoga de las mismas. Por ejemplo, al volver a mirar las vitrinas con los trofeos escolares, se podría problematizar la opción dicotómica "ordenadas" o "desordenadas" (LEDDY, 1995). El "orden" sólo existe para quien conoce el criterio ordenador, desde las condiciones del contexto en el que se sitúa. Es por esto que los trofeos de una Escuela Waldorf no se ven - ni huelen - ordenados del mismo modo que los de una Academia Militar, si bien ambas instituciones siguen reglas específicas respecto del orden de sus espacios y materiales.

Por esto, cabe preguntarse qué puede significar un premio para los éxitos estudiantiles en deportes y artes en el barrio concreto en que se halla emplazada esta escuela: para algunas comunidades estos trofeos podrían ser uno entre tantos, para otras, la primera oportunidad de practicar deportes o involucrarse en hacer arte. La atención sobre la cultura visual escolar desplegada en estas vitrinas motivaría interpretaciones acerca de los peculiares modos de concebir la educación que posee esta escuela; de la promesa sobre el desarrollo personal o profesional que ella puede encarnar; del trato entre directivos, profesores y estudiantes; de qué significa triunfar y ser reconocido aquí, entre otras. En breve, desde el esfuerzo por revelar la cultura visual escolar y analizar sus implicancias interpretativas, se comenzaría a proyectar la indisociable complejidad entre mirar, contexto y las relaciones intersubjetivas que se desarrollan allí mismo (DIKOVITSKAYA, 2006).

\section{Hacia el reconocimiento de estéticas visuales del clima escolar}

Esta última sección propone explorar teóricamente la percepción del entorno escolar, a través de la consideración de las relaciones interpersonales que se desarrollan en dicho ámbito. Esto, con la intención de complementar el desarrollo de sensibilidades más agudas y conscientes a través de la consideración estética de algunos aspectos del clima escolar que parecen ser decisivos a la hora de promover interacciones de calidad en la escuela.

La atención a las posibles relaciones entre el clima escolar ${ }^{5}$ y el entorno físico de la escuela se encuentra en un momento de creciente interés a nivel académico y de políticas públicas educativas (THAPA et al., 2013; GISLASON, 2009; 2010; ULINE et al., 2009; 2010; ULINE; TSCHANNEN-MORAN, 2008). Por ejemplo, es elocuente que junto con dimensiones como "la seguridad física" y el "sentido de pertenencia", el Observatorio Internacional de Violencia Escolar en Francia y el Centro Nacional de Clima Escolar de Estados Unidos juzgue a la 
"calidad de la infraestructura escolar" como un elemento central desde el cual abordar el mejoramiento del clima escolar (COHEN et al., 2009, p. 184).

En la misma dirección, es indicativo que la OECD, y en convergencia con lo señalado por Saito (2007) y Haapala (2005), considere que el "estado de los espacios comunes como muros, escaleras, baños y patios tienen una incidencia sobre la moral de los profesores y alumnos y, por lo tanto, sobre el clima escolar" (DEBARBIEUX et al., 2012, p. 4). De modo notable, esta institución ha reemplazado el Programa de Edificios Educativos (PEB) por el nuevo Centro para Ambientes Efectivos de Aprendizaje (CELE), enriqueciendo criterios físicos como "construcciones seguras" con la consideración del vínculo entre "la estética del edificio" y "la escuela en tanto lugar de vida comunitaria" (MUSSET, 2012, p. 13). Implícita está la influencia que las percepciones del espacio escolar -sus materialidades, imágenes, ambientes, tiempos, entre otras - tendrían sobre el grado de desarrollo de las relaciones entre estudiantes, profesores y directivos que viven en dicho entorno. En pocas palabras, se quiere prestar atención a lo que "los muros dicen” de la vida escolar (ULINE; TSCHANNEN-MORAN, 2008, p. 400).

Metodológicamente, en el afán de intentar comprender las posibles relaciones entre entorno y clima escolar, se han comenzado a utilizar técnicas basadas en imágenes tales como la foto-entrevista (CAPELLO, 2005). De este modo se pretende describir no solo qué se ve sino cómo se ven, y especialmente, cómo se sienten los espacios escolares, mediante las reacciones y descripciones que los propios involucrados hacen a un registro fotográfico elaborado por los investigadores y/o por ellos mismos (ULINE; DEVERE WOLSEY, 2011).

Lo cierto es que al intentar caracterizar aspectos del clima escolar como la "seguridad física", el "lugar de vida comunitaria" o la "calidad de la infraestructura escolar" parece inevitable recurrir a adjetivos, experiencias y ejemplos que surgen desde la percepción sensible. Junto con validar la relevancia que las estéticas cotidianas y la cultura visual escolar tienen de suyo, el esfuerzo por profundizar en las cualidades estéticas y visuales de estos mismos aspectos del clima escolar permitiría profundizar y enriquecer la comprensión de las relaciones que se dan al interior de la escuela.

Por ejemplo, al considerar a la escuela como un "lugar de vida comunitaria" se da por supuesta la existencia de una construcción que alberga, protege y ofrece un espacio de trabajo y juego. También se tiene la expectativa de relaciones humanas, compromisos y proyectos que se desplegarían en ese lugar. Pero la escuela en tanto "lugar de vida comunitaria" no se agota aquí. Se proyecta desde el contexto material e intersubjetivo hacia objetos de valor simbólico como las imágenes en las salas de clases, los colores institucionales, los puntos "ciegos" del patio o campo de deportes, las puertas de los baños, los sonidos y olores del recreo, entre otros signos que pueden ofrecer referencias de diálogo y convivencia. 
Dicho de otro modo, el intento por caracterizar estos aspectos del clima escolar permitiría revisitar cualidades de las sensibilidades que comparten quienes viven diariamente la escuela. Volvamos a mirar las Figuras 1, 2, 3, 4 y 5 . Parece una simplificación apresurada asumir que el pasillo de una escuela (Figuras 1 y 2) es meramente un conector entre el acceso, las salas de clases y el patio. Si bien puede cumplir con los requisitos arquitectónicos que velan por la "seguridad física", un pasillo escolar puede ser vivido como un refugio, un patio de juegos, un campo de batalla, o incluso tierra de nadie entre trincheras. De un modo semejante, la vitrina de trofeos (Figuras 3, 4 y 5) es más que la exhibición de logros estudiantiles. Ella puede evocar simbólicamente un "lugar de vida comunitaria" que promueve los esfuerzos compartidos entre amigos, la vida saludable y la autosuperación, pero también manifestar aires de individualismo, exitismo, o menosprecio de quienes no se involucran en las actividades premiadas.

Este diálogo entre estéticas cotidianas y clima escolar, si bien preliminar y tentativo, es importante al considerar la pregunta originaria por la contribución que éstas pueden hacer a la educación escolar. Si como se propone en las primeras secciones de este artículo, la escuela enseña a percibir, especialmente a mirar, entonces es legítimo suponer que también puede condicionar el modo en que los sujetos aprenden a sentirse y relacionarse entre ellos. Desde este punto de vista es que se podría comprender todavía mejor por qué una escuela que no "alberga" (FLORES, 2015, p. 106) o no "promueve el vínculo entre el ambiente de la sala de clases y la pertenencia a la escuela" (SHOCHET; SMITH, 2014, p. 490) o no incentiva "más participación estudiantil" (HIGGINS et al., 2005, p. 23) condicionaría un clima escolar de bajo nivel.

Dicho positivamente, una escuela que se vea y sienta como un "lugar de vida comunitaria", con "infraestructura escolar de calidad" y "espacios seguros", favorecería un clima escolar no sólo adecuado sino más rico y significativo para quienes viven la escuela. En ella, el entorno físico y las relaciones intersubjetivas de sus miembros podrían visualizarse en tanto expresiones concomitantes que contribuirían al desarrollo de una experiencia escolar de mayor lucidez y potencial crítico.

\section{Conclusiones}

Si bien las estéticas cotidianas escolares no han recibido mucha atención por parte de la investigación educativa, a partir de ellas podrían realizarse diversas contribuciones, comenzando por tematizar la relación entre la percepción del espacio escolar y el grado de desarrollo de las relaciones entre quienes habitan y conforman la escuela.

En primer lugar, esto implicaría proponer las bases para una alfabetización sensible en tanto condición desde la cual abordar cualquier otro tipo de 
alfabetización escolar. Retomando el ejemplo de Helen Keller, nombrar lo que se ve, expresar lo que se siente, ser más consciente de cómo se siente lo que se conoce, no son patrimonio de algunos pocos elegidos sino potenciales comunes a todos los seres humanos en tanto seres sintientes e inteligentes.

A este respecto el rol de la escuela es ineludible, ya que enseñar y aprender supone una toma de posición - ojalá explícita - sobre cómo percibir aquello que se enseña y aprende. En otras palabras, la escuela tiene responsabilidad en interrumpir - o no - la transparencia de los significados y modos como comúnmente se aborda la sensibilidad, por ejemplo, problematizando lugares y dispositivos tales como los pasillos o las vitrinas de trofeos que suelen permanecer ocultos o invisibles por la costumbre de ver siempre de la misma manera.

En segundo lugar, atender a las estéticas cotidianas escolares permitiría aprovechar el arsenal simbólico de las escuelas, sus materialidades, disposiciones y rutinas para avanzar en la comprensión de las relaciones subjetivas que entre estas dimensiones se desarrollan. Aquí las matrices estéticas pueden ayudar a profundizar las distintas propuestas pedagógicas a través de la explicitación simbólica de las condiciones en donde se vive, de hecho, la realidad escolar.

Por ejemplo, formular comunitariamente la matriz estética del propio establecimiento tendría el potencial de revelar la imagen que no sólo los sujetos tienen de sí mismos y de su entorno, sino - especialmente - de la calidad de relaciones y sentidos que supone la educación. Es decir, discutir de qué manera la comunidad ve y siente el proyecto educativo institucional a través del entorno escolar construido, de las decisiones pedagógicas, del aprovechamiento de los espacios, del uso del tiempo, entre otros.

Finalmente, no basta con proclamar la relevancia de que la escuela se constituya como un lugar de vida comunitaria. Es justo que este lugar se quiera ver, que los signos de pertenencia se puedan constatar, la apropiación emocional del espacio se plasme en la materia de la escuela y el entrecruzamiento de las subjetividades se muestre. Después de todo, si la escuela pretende cumplir con su mandato de enseñar a vivir una vida verdaderamente humana, la relación entre lo que se ve y cómo se siente, debiera estar al centro de sus preocupaciones.

\section{Notas}

1. Utilizamos la noción de "alfabetización sensible" en un sentido amplio, sin adscribir todavía a un autor o escuela de pensamiento particular. Sí, anticipamos que la capacidad de detenerse en la propia sensibilidad en la escuela, comprendiendo el modo en que se percibe, supone desarrollar un lenguaje capaz de relevar, problematizar e intervenir la relación entre sensibilidad y experiencia humana. Considérese más adelante en el texto el ejemplo de Helen Keller. 
2. Si bien la distinción y relación entre "espacio" y "lugar" excede las posibilidades de este artículo, es justo remarcar los aportes de geógrafos como Yi-Fu Tuan y John Agnew. Ellos permiten dilucidar las implicancias prácticas de diversos modos de relacionarse con el mundo que todos habitamos (Ver por ejemplo: TUAN, 2014; AGNEW; LIVINGSTONE, 2011). De modo llamativo, mientras que arquitectos y diseñadores comparten durante su formación el estudio de las nociones de "espacio" y "lugar", los educadores suelen carecer de instrucción específica al respecto.

3. La inquietud obvia por otras culturas escolares que no sean visuales es tan fascinante como poco explorada. Por ejemplo, si la investigación sobre los ruidos y los sonidos escolares es escasa en comparación con los estudios sobre la luz y los colores (HIGGINS et al., 2005), la pregunta sobre los olores y las texturas de la escuela parece francamente desierta.

4. Ya reconocemos hacia el año 1903 a Fernando Fusoni como uno de los precursores de este argumento. Su discusión sobre el lugar que debieran ocupar las imágenes escolares, su temática, la frecuencia de cambio o permanencia de las mismas, entre otras características decisivas de la cultura visual escolar, es impresionante por su precisión y expresión (Ver por ejemplo: FUSONI, 1903).

5. Si bien no existe una definición última de clima escolar en tanto fenómeno emergente y multidimensional, a efectos de este artículo se adoptará la que comparten el Observatorio Internacional de Violencia Escolar de Francia (DEBARBIEUX et al., 2012) y el Centro Nacional de Clima Escolar de los Estados Unidos): "El clima escolar está basado en los modelos de experiencias subjetivas de la vida escolar; y refleja normas, metas, valores, relaciones intersubjetivas, prácticas de enseñanza y aprendizaje, y estructuras organizacionales" (NSCC, 2007, p. 5).

\section{Referencias}

AGNEW, J.; LIVINGSTONE, D. Handbook of Geographical Knowledge. London: Sage, 2011.

BAKER, L. A History of School Design and its Indoor Environmental Standards, 1900 to Today. Washington, D.C.: National Clearinghouse for Educational Facilities, jan. 2012. p. 1-30. Disponible en: <http://www.ncef.org/pubs/greenschoolshistory.pdf $>$. Acceso en: 9 nov. 2016.

BIESTA, G. ¿Medir lo que valoramos o valorar lo que medimos? Globalización, responsabilidad y la noción de propósito de la educación. Pensamiento Educativo, v. 51, n. 1, p. 46-57, 2014. Disponible en: <http://pensamientoeducativo.uc.cl/index.php/pel/ article/view/618/1259>. Acceso en: 11 nov. 2016.

BRYSON, N. The Gaze in the Expanded Field. In: FOSTER, H. (Org.). Vision and Visuality. Washington, D.C.: Bay View Press, 1988. p. 87-114.

CAPELLO, M. Photo interviews: eliciting data through conversations with children. Field Methods, v. 17, n. 2, p. 170-182, 2005. 
COHEN, J.; MCCABE, E. M.; MICHELLI, N. M.; PICKERAL, T. School Climate: Research, Policy, Practice, and Teacher Education. Teachers College Record, v. 111, n. 1, p. 180-213, jan. 2009. Disponible en: shttp://ww.ijvs.org/files/Publications/SchoolClimate.pdf $>$. Acceso en: 9 nov. 2016.

DAMASIO, A. Self comes to mind: constructing the conscious brain. New York: Vintage, 2010.

. The feeling of what happens: body and emotion in the making of consciousness. New York: Harvest, 2000.

DEBARBIEUX, E.; ANTON, N.; ASTOR, R. A.; BENBENISHTY, R.; BISSONVAIVRE, C.; COHEN, J.; GIORDAN, A.; HUGONNIER, B.; NEULAT, N.; ORTEGA RUIZ, R.; SALTET, J.; VELTCHEFF, C.; VRAND, R. Le "Climat scolaire": définition, effets et conditions d'amélioration. Rapport au Comité scientifique de la Direction de l'enseignement scolaire, Ministère de l'éducation nationale. MEN-DGESCO/ Observatoire International de la Violence à l'École, 2012. Disponible en: <http://www. cafepedagogique.net/lexpresso/Documents/docsjoints/climat-scolaire2012.pdf>. Acceso en: 9 nov. 2016.

DEWEY, J. Art as Experience. New York: Perigee, 1934.

DIKOVITSKAYA, M. Visual Culture: the study of the visual after the cultural turn. Massachusetts: MIT Press, 2006.

DOWLING, C. The Aesthetics of Daily Life. British Journal of Aesthetics, v. 50, n. 3, p. 225-242, 2010.

EISNER, E. Does Arts-Based Research Have a Future? Studies in Art Education, v. 48, n. 1, p. 9-18, 2006.

. What Education Can Learn from the Arts? Art Education, v. 62, n. 2, p. 6-9, 2009.

ERRÁZURIZ, L. H. Calidad Estética del Entorno Escolar: el (f)actor invisible. Arte, Individuo y Sociedad, v. 27, n. 1, p. 81-100, 2015 a.

. El (f)actor invisible: estética cotidiana y cultura visual en espacios escolares. Santiago: Ediciones Cultura, 2015b.

ERRÁZURIZ, L. H.; MARINI, G. Chilean School Façades: Aesthetic Matrixes, Educational Insights, Visual Communication, v. 15, n. 4, p. 429-438, 2016. Disponible en: <http://journals.sagepub.com/doi/full/10.1177/1470357215616066>. Acceso en: 21 oct. 2017.

FLORES, L. La cuestión del clima y el espacio escolar: lineamientos y proyecciones pedagógicas. In: ERRÁZURIZ, L. H. (Org.). El (f)actor invisible: estética cotidiana y cultura visual en espacios escolares. Santiago: Ediciones Cultura, 2015. p. 101-110 Disponible en: shttp://www.cultura.gob.cl/wp-content/uploads/2015/11/factor invisible digital.pdf>. Acceso en: 9 nov. 2016.

FUSONI, F. La imagen en la escuela. El monitor de la educación común, v. 22, p. 73-75, 1903. 
GADAMER, H. G. La actualidad de lo bello: el arte como juego, símbolo y fiesta. Madrid: Paidós Ibérica, 1991.

GISLASON, N. Architectural design and the learning environment: a framework for school design research. Learning Environments Research, v. 13, n. 2, p. 127-145, jul. 2010. Disponible en: $\leq$ http://link.springer.com/article/10.1007\%2Fs10984-010-9071-x>. Acceso en: 9 nov. 2016.

Mapping School Design: a Qualitative Study of the Relations Among Facilities Design, Curriculum Delivery, and School Climate. The Journal of Environmental Education, v. 40, n. 4, p. 17-34, 2009. Disponible en: $\leq$ http://www.tandfonline.com/doi/ abs/10.3200/JOEE.40.4.17-34>. Acceso en: 9 nov. 2016.

HAAPALA, A. On the Aesthetic of the Everyday. In: LIGHT, A.; SMITH, J. (Org.). The Aesthetics of Everyday Life. New York: Columbia University Press, 2005. p. 39-55.

HARGREAVES, A. Changing Teachers, Changing Times: Teachers' Work and Culture in the Postmodern Age. New York: Teachers College Press, 2012.

HIGGINS, S.; HALL, E.; WALL, K.; WOOLNER, P.; MCCAUGHEY, C. The impact of school environments: a literature review. United Kingdom: Design Council, 2005.

HUSTI, A. Del tiempo escolar uniforme a la planificación móvil del tiempo. Revista de Educación, n. 298, p. 271-305, maio 1992. Disponible en: <https:// www.mecd.gob.es/dctm/revista-de-educacion/articulosre298/re2981200486. pdf?documentId=0901e72b8135769a>. Acceso en: 17 nov. 2016.

LEDDY, T. Everyday surface aesthetic qualities: "Neat," “messy," "clean," "dirty". Journal of Aesthetics and Art Criticism, v. 53, n. 3, p. 259-268, jul. 1995. Disponible en: <http://www.jstor.org/stable/431351>. Acceso en: 9 nov. 2016.

. The Extraordinary in the Ordinary: The Aesthetics of Everyday Life. Peterborough, Canada: Broadview Press, 2012.

LEHTINEN, S. Personal Space and the Everyday Aesthetic Experience - Chasing after Boundaries and Definitions. In: INTERNATIONAL CONGRESS OF AESTHETICS AESTHETICS IN ACTION, 19., 2013, Cracovia. Disponible en: shttps://www.academia. edu/4167312/Personal Space and Everyday Aesthetic Experience $>$. Acceso en: 9 nov. 2016.

LIPPMAN, P. Evidence-Based Design of Elementary and Secondary Schools: A Responsive Approach to Creating Learning Environments. New Jersey: Wiley, 2010.

LOWENFELD, V. Desarrollo de la capacidad creadora. Buenos Aires: Kapelusz, 1970.

MANDOKI, K. Everyday Aesthetics: Prosaics, the Play of Culture and Social Identities. United Kingdom: Ashgate, 2007.

MARGOLIS, E. Class pictures: Representations of race, gender and ability in a century of school photography. Visual Sociology, v. 14, n. 1-2, p. 7-38, 1999.

MARINI, G. A primordial sense of art. Journal of Aesthetic Education, v. 50, n. 1, p. 46-61, 2016. Disponible en: <http://www.jstor.org/stable/10.5406/jaesteduc.50.1.0046>. Acceso en: 21 oct. 2017. 
- Percibir y educar: orientaciones pedagógicas a partir de Elliot Eisner. In: ERRÁZURIZ, L.H. (Org.). El (f)actor invisible: Estética cotidiana y cultura visual en espacios escolares. Santiago: Ediciones Cultura, 2015. p. 111-120. Disponible en: <http://www.cultura.gob.cl/wp-content/uploads/2015/11/factor invisible digital. pdf>. Acceso en: 21 oct. 2017.

MIRZOEFF, N. An Introduction to Visual Culture. London: Routledge, 1999.

MUSSET, M. De l'architecture scolaire aux espaces d'apprentissage: au bonheur d'apprendre? Dossier d' actualité, Institut français de l'Éducation, v. 75, p. 1-19, mayo 2012. Disponible en: shttp://ife.ens-lyon.fr/vst/DA-Veille/75-mai-2012.pdf . Acceso en: 9 nov. 2016.

NATIONAL SCHOOL CLIMATE COUNCIL (NSCC). The School Climate Challenge: Narrowing the gap between school climate research and school climate policy, practice guidelines and teacher education policy. 2007. Disponible en: $\leq$ http://www.schoolclimate. org/climate/documents/school-climate-challenge.pdf $>$. Acceso en: 10 nov. 2016.

PALLASMAA, J. Los ojos de la piel: la arquitectura y los sentidos. Barcelona: Gustavo Gili, 2006.

PINEAU, P. Escolarizar lo sensible: estudios sobre estética escolar (1870-1945). Buenos Aires: Teseo, 2014.

PROSSER, J. Visual Methods and the visual culture of schools. Visual Studies, v. 22, n. 1, p. 13-30, abr. 2007. Disponible en: <http://www.publicsphere.narod.ru/VisCultSchools. pdf>. Acceso en: 9 nov. 2016.

RANCIÈRE, J. El reparto de lo sensible: estética y política. Santiago: LOM, 2009.

ROSE, G. Visual Methodologies. London: Sage, 2012.

SAITO, Y. Everyday Aesthetic. New York: Oxford University Press, 2007.

SHOCHET, I.M.; SMITH, C.L. A prospective study investigating the links among Classroom environment, School connectedness, and Depressive symptoms in adolescents. Psychology in the Schools, v. 51, n. 5, p. 480-492, may. 2014. Disponible en: <http:// onlinelibrary.wiley.com/doi/10.1002/pits.21759/full>. Acceso en: 10 nov. 2016.

SHUSTERMAN, R. Body Consciousness: a Philosophy of Mindfulness and Somaesthetics. New York: Cambridge University Press, 2008.

SMITH, M. Visual Culture Studies: Interviews with Key Thinkers. London: Sage, 2008.

STURKEN, M.; CARTWRIGHT, L. Practices of Looking: An Introduction to Visual Culture. Oxford: Oxford University Press, 2001.

SULLIVAN, A. Carta del 5 de Abril de 1887 narrando la educación de Hellen Keller. 1887. Disponible en: <http://www.afb.org/MyLife/book.asp?ch=P3Ch3\&select=1\#1 . Acceso en: 11 nov. 2016.

THAPA, A.; COHEN, J.; GUFFEY, S.; D'ALESSANDRO, A.H. A review of School Climate Research. Review of Educational Research. Review of Educational Research, v. 83, n. 3, p. 357-385, sep. 2013. Disponible en: $\leq$ http://rer.sagepub.com/content/83/3/357. full.pdf+html>. Acceso en: 9 nov. 2016. 
THOMPSON, P. Doing Visual Research with Children and Young People. United Kingdom: Routledge, 2008.

TUAN, Yi-Fu Space and Place: the perspective of experience. Minneapolis: University of Minnesota Press, 2014.

ULINE, C.; DEVERE WOLSEY, T.; TSCHANNEN-MORAN, M.; LIN, C.-D. Improving the physical and social environment of school: a question of equity. The Journal of School Leadership, v. 20, p. 597-632, sep. 2010. Disponible en: <http://assets.efc.gwu. edu/resources/repository/116/Uline ImprovingthePhysical.pdf $>$. Acceso en: 9 nov. 2016.

ULINE, C.; DEVERE WOLSEY, T.D. Exploring learning spaces and places: The photo interview. Educational Facility Planner, v. 45, n. 1-2, p. 24-27, 2011. Disponible en: shttp://media.cefpi.org/efp/EFP45-1and2Uline-Wolsey.pdf>. Acceso en: 9 nov. 2016.

ULINE, C.; TSCHANNEN-MORAN, M. The walls speak: the interplay of quality facilities, school climate and student achievement. Journal of Educational Administration, v. 46, n. 1, p. 55-73, 2008.

ULINE, C.; TSCHANNEN-MORAN, M.; DEVERE WOLSEY, T. The walls still speak: the stories occupants tell. Journal of Educational Administration, v. 47, n. 3, p. 400-426, 2009.

Recibido el 14 de noviembre de 2016.

Aceptado el 07 de noviembre de 2017.

(C) 2018 Centro de Estudos Educação e Sociedade - CEDES Este é um artigo de acesso aberto distribuído nos termos de licença Creative Commons. 